\title{
Epidemiology of Spinal Cord Injury: Changes to Its Cause Amid Aging Population, a Single Center Study
}

\author{
Ha Seong Kim, MD, Kill-Byung Lim, MD, PhD, Jiyong Kim, MD, PhD, \\ Joongmo Kang, MD, Hojin Lee, MD, Sang Wan Lee, MD, Jeehyun Yoo, MD
}

Department of Physical Medicine and Rehabilitation, Inje University Ilsan Paik Hospital, Goyang, Korea

Objective To investigate the epidemiologic and demographic characteristics of patients with spinal cord injury (SCI) who were admitted to a department of rehabilitation of a university hospital.

Methods This was a descriptive cross-sectional study. Medical records including sex, age at injury, type of disability, traumatic or non-traumatic etiology and presence of ossification of posterior longitudinal ligament (OPLL) of patients with SCI who were admitted to the department of rehabilitation between 2012 and 2018 were reviewed.

Results Of the 221 cases of SCI, 161 were traumatic and 60 were non-traumatic. The mean age at injury was 52.8 years. People aged 40-49 years showed highest proportion among overall SCI patients (19.0\%). The proportion of male patients was higher in traumatic SCI at 4.96:1 than in non-traumatic SCI at 1.30:1. The most common cause of traumatic SCI was falling off (37.3\%), followed by motor vehicle crash (35.4\%) and tripping over (19.3\%). Meanwhile, the most common cause of non-traumatic SCI was neoplasm (35.0\%). Tripping over was the leading cause of traumatic SCI in patients aged $\geq 60$ years (42.6\%). A high proportion of traumatic SCI patients were found to have underlying OPLL (26.1\%), particularly those who were injured by tripping over $(64.5 \%)$.

Conclusion The mean age of SCI patients was higher than that of previous studies. Falls was the single most common cause of traumatic SCI, and tripping over was the most common cause of injury in the elderly patients. OPLL was prevalent in patients who were injured from tripping over.

Keywords Spinal cord injuries, Epidemiology, Ossification of posterior longitudinal ligament, Accidental falls

Received July 21, 2020; Revised August 19, 2020; Accepted August 24, 2020; Published online February 9, 2021

Corresponding author: Jeehyun Yoo

Department of Physical Medicine and Rehabilitation, Inje University Ilsan Paik Hospital, 170 Juhwa-ro, Ilsanseo-gu, Goyang 10380, Korea. Tel: +82-31910-7440, Fax: +82-31-910-7446, E-mail: jhyoo@paik.ac.kr

ORCID: Ha Seong Kim (http://orcid.org/0000-0001-5121-1244); Kil-Byung Lim (http://orcid.org/0000-0001-8971-7486); Jiyong Kim (http://orcid. org/0000-0003-4693-8400); Joongmo Kang (http://orcid.org/0000-0003-3133-9202); Hojin Lee (http://orcid.org/0000-0002-0304-344X); Sang Wan Lee (http://orcid.org/0000-0003-1310-3853); Jeehyun Yoo (http://orcid.org/0000-0002-1555-8029).

(c) This is an open-access article distributed under the terms of the Creative Commons Attribution Non-Commercial License (http://creativecommons.org/ licenses/by-nc/4.0) which permits unrestricted noncommercial use, distribution, and reproduction in any medium, provided the original work is properly cited. Copyright () 2021 by Korean Academy of Rehabilitation Medicine 


\section{INTRODUCTION}

Spinal cord injury (SCI) is one of the major insults to the central nervous system that results in persisting physical and psychological sequelae, thereby incurring tremendous socioeconomic costs related to health care treatment, rehabilitation, and loss of productivity [1-4]. Therefore, extensive efforts for predicting and preventing SCI should be made to improve national health and welfare. Educational programs that are designed based on epidemiologic studies have shown to be successful in reducing the incidence of traumatic SCI [5-8]. In the United States, epidemiologic changes in age, sex, and completeness of injury of SCI are continuously being monitored by the National Spinal Cord Injury Statistical Center (NSCISC), and a gradual increase in the prevalence of the people with old age, female sex, and incomplete injury has been reported [9-12]. In Asia, only Japan and Taiwan are counting and registering traumatic SCI people in the perspective of epidemiology. Other Asian countries, including Korea, do not take the same approach [13]. Particularly, in Korea, people with SCI are being counted as having "physical disability" and clustered together with other disabilities; thus, the exact incidence of SCI can only be assumed indirectly [14]. Some of the most recent studies in Korea that analysed national demographic data specific to SCI were those by Park et al. [15], Shin et al. [16], and by the National Rehabilitation Center [17]. Park et al. [15] reported traffic accidents as the most common cause of traumatic SCI, accounting for $57.6 \%$, and falls as the second most common cause, accounting for $26.4 \%$ in 1999. However, the study by the National Rehabilitation Center in 2014 [17] showed that the percentage of SCI caused by traffic accidents had decreased from $64 \%$ in $1994-2000$ to $45 \%$ in $2008-2014$. The proportion of falls had risen from $23 \%$ to $43 \%$ during the same time intervals, implying a change in trends regarding the etiology of traumatic SCI.

There are many explanations and hypotheses in interpreting the changes in SCI epidemiology worldwide, and understanding each country's demographic characteristics and cultural specificity in connection with etiology is important in interpretation. For example, falls account for $63.0 \%$ of SCI in Bangladesh, which is a developing Asian country with a low-income economy and a small urban population. Those injuries mostly occur among those aged between 10 years and 40 years and are mainly attributed to falling from trees or carrying heavy objects on the head. Meanwhile, in eastern Canada, which is a developed country with a high-income economy and a large urban population, the mean age at the time of SCI was 55.4 years, and falls accounted for only $19.1 \%$ of SCI etiology. However, falls were the leading cause of SCI in the elderly (i.e., age $\geq 60$ years), accounting for $47 \%$ [18].

One of the most remarkable demographic characteristics of Korea is rapid aging of population, and this is occurring in many developed nations including those in Europe $[19,20]$. Data from Statistics Korea show that in $2018,14.3 \%$ of the population were aged $\geq 65$ years, and this proportion is projected to increase to $35.9 \%$ by 2050 and to $41.0 \%$ by $2060[21,22]$.

On the other hand, one of other characteristics of Korean population is high prevalence of ossification of posterior longitudinal ligament (OPLL), which is thought to be related to incurring cervical SCI with minor trauma [23-25]. OPLL is pathological calcification of posterior longitudinal ligament, which occurs more frequently in Asian population than other races [26] and most commonly at the cervical spine [27]. Depending on the size, OPLL can results in the spinal canal narrowing and more importantly, compression of the spinal cord and traumainduced sudden onset myelopathy. The mainstay treatment of OPLL is surgical decompression, including corpectomy, laminectomy, and combined fusion [27].

This study aimed to investigate the effect of demographic changes on SCI epidemiology in Korea with cross-sectional data of single university hospital. We hypothesized that an aging population might present more injuries caused by minor traumas such as low falls including slip-down and tripping over even in level ground or in the stairs, as in other developed countries. We also hypothesized that increase in mean age of SCI people might be related to more comorbidities of degenerative diseases such as OPLL, which contributes to SCI. To determine the impact of population aging on changes in SCI etiology, we separated falls into two categories, namely, high-energy trauma and low-energy trauma, by separately calculating the high falls (falling off) and low falls (tripping over). 


\section{MATERIALS AND METHODS}

\section{Study design and subjects}

This was a descriptive cross-sectional study of individuals with SCI from traumatic or non-traumatic causes who were hospitalized for comprehensive rehabilitation to a dedicated hospital between January 2012 and June 2018 . Data on demographic, injury, and medical characteristics were obtained from hospital admission records. This study was approved by Inje University Ilsan Paik Hospital Institutional Review Board (No. 2020-03-027). SCI was defined as the event of a traumatic or non-traumatic lesion of neural elements in the spinal canal that resulted in temporary or permanent sensory and/or motor deficit [28].

Descriptive analyses of SCI are suggested with stratification by key demographic characteristics and SCI- specific characteristics (e.g., sex, age at injury, American Spinal Injury Association Impairment Scale [AIS] score at admission and discharge, SCI type, and etiology) according to the International Spinal Cord Society guidelines, where possible [29].

\section{Categorization of falls}

Falls were categorized into low $(<1 \mathrm{~m})$ or high falls $(\geq 1$ $\mathrm{m}$ ) based on available information on cause of injury in the medical records [28]. A 1-m cutoff for classifying the level of falls was chosen to facilitate comparison with previous reports in the literature and with reference to the World Health Organization's (WHO's) International Perspectives on SCI report. The WHO report categorized falls into 4 different patterns: (1) falls on the same level, (2) falls from heights of $<1 \mathrm{~m}$, (3) falls from heights of $\geq 1$ $\mathrm{m}$, and (4) being struck by a falling object [30]. We classi-

Table 1. Study characteristics by spinal cord injury etiology

\begin{tabular}{|c|c|c|c|c|}
\hline Variable & Traumatic & Non-traumatic & Overall & p-value ${ }^{a)}$ \\
\hline Sex & & & & $<0.001$ \\
\hline Male & $134(83.2)$ & $34(56.7)$ & $168(76.0)$ & \\
\hline Female & $27(16.8)$ & $26(43.3)$ & $53(24.0)$ & \\
\hline Mean age at injury & $49.8 \pm 18.0(14-86)$ & $60.7 \pm 15.2(17-86)$ & $52.8 \pm 17.9(14-86)$ & \\
\hline $\begin{array}{l}\text { Mean time after injury onset } \\
\text { to admission/transfer (day) }\end{array}$ & $374.3 / 1,086.3$ & $631.4 / 2,323.3$ & $444.1 / 1,522.8$ & \\
\hline Age at injury (yr) & & & & $<0.001$ \\
\hline $10-19$ & $11(6.8)$ & $1(1.7)$ & $12(5.4)$ & \\
\hline $20-29$ & $11(6.8)$ & $0(0)$ & $11(5.0)$ & \\
\hline $30-39$ & $25(15.5)$ & $5(8.3)$ & $30(13.6)$ & \\
\hline $40-49$ & $34(21.1)$ & $8(13.3)$ & $42(19.0)$ & \\
\hline $50-59$ & $26(16.1)$ & $12(20.0)$ & $38(17.2)$ & \\
\hline $60-69$ & $27(16.8)$ & $13(21.7)$ & $40(18.1)$ & \\
\hline $70-79$ & $22(13.7)$ & $16(26.7)$ & $38(17.2)$ & \\
\hline $80-89$ & $5(3.1)$ & $5(8.3)$ & $10(4.5)$ & \\
\hline AIS & & & & $<0.001$ \\
\hline A & $54(33.5)$ & $2(3.3)$ & $56(25.3)$ & \\
\hline B & $9(5.6)$ & $1(1.7)$ & $10(4.5)$ & \\
\hline $\mathrm{C}$ & $29(18.0)$ & $8(13.3)$ & $37(16.7)$ & \\
\hline $\mathrm{D}$ & $69(42.9)$ & $49(81.7)$ & $118(53.4)$ & \\
\hline Type of disability & & & & 0.001 \\
\hline Tetraplegia & $103(64.0)$ & $24(40.0)$ & $127(57.5)$ & \\
\hline Paraplegia & $58(36.0)$ & $36(60.0)$ & $94(42.5)$ & \\
\hline
\end{tabular}

Values are presented as number (\%) or mean \pm standard deviation (min-max).

AIS, American Spinal Injury Association impairment scale.

${ }^{\text {a) }}$ Pearson chi-square test comparing traumatic and non-traumatic spinal cord injury. 
fied categories 1 and 2 as low fall (tripping over), and 3 as high fall (falling off). There was no case for category 4 in this study.

\section{Statistical analysis}

Descriptive statistics (mean, standard deviation, frequency, ratio, and percentage) were used to describe the clinicodemographic characteristics of the study participants across injury etiologies. Student t-test and chi-square test, as appropriate, were used to assess the differences between the etiology groups at a statistical significance level of 0.05. All analyses were performed using the IBM Statistical Package for the Social Sciences, software version 22.0 (IBM Corp., Armonk, NY, USA).

\section{RESULTS}

\section{Epidemiology and demographics}

In total, 221 cases of SCI were included in the study. Of these, 161 were traumatic and 60 were non-traumatic. In the traumatic SCI group, $134(83.2 \%)$ were men and 34 (16.8\%) were women; in the non-traumatic SCI group, $27(56.7 \%)$ were men and $26(43.3 \%)$ were women. The proportion of male patients was noticeably higher in the traumatic SCI group at 4.96:1 than in the non-traumatic SCI group at 1.30:1. The mean age of the overall cohort was $52.8 \pm 17.9$ years, and that of the traumatic and the non-traumatic SCI groups were $49.8 \pm 18.0$ and $60.7 \pm 15.2$ years, respectively. The patient characteristics are shown in Table 1. The proportion of the 40-49 year age group was the highest among overall patients (19.0\%), and majority $(21.1 \%)$ of patients in the traumatic SCI group were also aged $40-49$ years. Meanwhile, majority (26.7\%) of patients in the non-traumatic SCI group were aged 70-79 years.

\section{Etiology}

With respect to etiology, falling off was the most common cause of traumatic SCI ( $\mathrm{n}=60 / 161,37.3 \%)$, followed by motor vehicle crashes (MVC) ( $\mathrm{n}=57,35.4 \%)$ (Table 2 ). Categorizing tripping over and falling off $(n=31,19.3 \%)$ together as falls, it becomes a more dominant cause of traumatic SCI, accounting for $56.5 \%$. The age distribution according to the detailed trauma etiology is shown in Table 2. The most common cause of SCI varied in each age group. In the 10-19, 20-29, and 50-59 years age group,

Table 2. Type and severity of injury, number of cases of each traumatic etiology according to age group

\begin{tabular}{|c|c|c|c|c|c|c|}
\hline Traumatic etiology & MVC & Fall off & Trip over & Sports injury & Others & Overall \\
\hline Number of cases (\%) & $57(35.4)$ & $60(37.3)$ & $31(19.3)$ & $7(4.3)$ & $6(3.7)$ & $161(100)$ \\
\hline Mean age at injury & $48.3 \pm 15.4$ & $46.0 \pm 18.5$ & $62.9 \pm 16.9$ & $33.1 \pm 9.9$ & $53.5 \pm 12.2$ & $49.8 \pm 18.0$ \\
\hline \multicolumn{7}{|c|}{ Type and severity of injury ${ }^{a}$} \\
\hline Complete tetraplegia & $8(14.0)$ & $11(18.3)$ & $4(12.9)$ & $3(42.9)$ & $0(0)$ & $26(16.1)$ \\
\hline Incomplete tetraplegia & $33(57.9)$ & $13(21.7)$ & $23(74.2)$ & $4(57.1)$ & $4(66.7)$ & $77(47.8)$ \\
\hline Complete paraplegia & $8(14.0)$ & $18(30.0)$ & $0(0)$ & $0(0)$ & $2(33.3)$ & $28(17.4)$ \\
\hline Incomplete paraplegia & $8(14.0)$ & $18(30.0)$ & $4(12.9)$ & $0(0)$ & $0(0)$ & $30(18.6)$ \\
\hline \multicolumn{7}{|l|}{ Age at injury ${ }^{\mathrm{b})}(\mathrm{yr})$} \\
\hline $10-19$ & $3(5.3,27.3)$ & $6(10.0,54.5)$ & $1(3.2,9.1)$ & $1(14.3,9.1)$ & $0(0,0)$ & $11(6.8,100)$ \\
\hline $20-29$ & $3(5.3,27.3)$ & $7(11.7,63.6)$ & $0(0,0)$ & $1(14.3,9.1)$ & $0(0,0)$ & $11(6.8,100)$ \\
\hline $30-39$ & $9(15.8,36.0)$ & $9(15.0,36.0)$ & $3(9.7,12.0)$ & $3(42.9,12.0)$ & $1(16.7,4.0)$ & $25(15.5,100)$ \\
\hline $40-49$ & $16(28.1,47.1)$ & $12(20.0,35.3)$ & $3(9.7,8.8)$ & $2(28.6,5.9)$ & $1(16.7,2.9)$ & $34(21.1,100)$ \\
\hline $50-59$ & $11(19.3,42.3)$ & $12(20.0,46.2)$ & $1(3.2,3.8)$ & $0(0,0)$ & $2(33.3,7.7)$ & $26(16.1,100)$ \\
\hline $60-69$ & $9(15.8,33.3)$ & $6(10.0,22.2)$ & $10(32.3,37.0)$ & $0(0,0)$ & $2(33.3,7.4)$ & $27(16.8,100)$ \\
\hline $70-79$ & $6(10.5,27.3)$ & $7(11.7,31.8)$ & $9(29.0,40.9)$ & $0(0,0)$ & $0(0,0)$ & $22(13.7,100)$ \\
\hline $80-89$ & $0(0,0)$ & $1(1.7,20.0)$ & $4(12.9,80.0)$ & $0(0,0)$ & $0(0,0)$ & $5(3.1,100)$ \\
\hline
\end{tabular}

Values are presented as number (\%) or mean \pm standard deviation.

MVC, motor vehicle crashes.

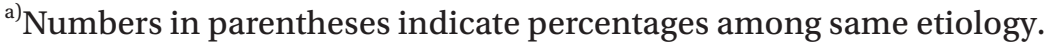

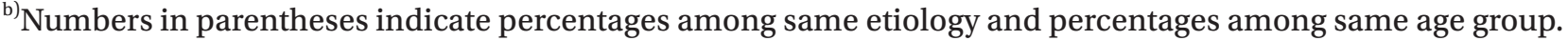


falling off was the most common cause of traumatic SCI, accounting for $54.5 \%, 63.6 \%$, and $46.2 \%$, respectively. Meanwhile, in those aged 60 years or older, tripping over was the leading cause of traumatic SCI, accounting for $37.0 \%, 40.9 \%$, and $80.0 \%$ in the $60-69,70-79$, and $80-89$ years age groups, respectively. The mean age of each traumatic etiology was also distinct from each other. Particularly, patients who were injured by tripping over showed a significantly higher mean age of $62.9 \pm 16.9$ years compared to patients with other etiologies ( $\mathrm{p}<0.001)$.

The mean age and AIS score and the detailed number of cases of non-traumatic etiology are shown in Table 3. The most common cause of non-traumatic SCI was neoplasm, accounting for $35.0 \%$. The mean age of each etiology was mostly over 60 years, except for infectious disease and other non-traumatic causes, which was at 59.1 and 56.6 years, respectively. There were only two patients who presented complete injury (AIS-A), while the other 58 patients were incompletely injured by non-traumatic causes.

\section{Type of disability and severity of injury}

The types of disabilities and severity of injury caused by SCI are detailed in Table 2 . The majority (47.8\%) of traumatic SCI patients presented incomplete tetraple- gia, except patients who were injured by falling off. Most (74.2\%) of the patients who were injured by tripping over presented incomplete tetraplegia. Non-traumatic causes of SCI most commonly resulted in incomplete paraplegia (58.3\%) followed by incomplete tetraplegia (38.3\%).

\section{Prevalence of OPLL in traumatic SCl patients}

Table 4 shows the number of patients with OPLL in the traumatic SCI group. In total, 42 patients $(26.1 \%)$ were found to have underlying OPLL. The prevalence of OPLL in patients who were injured by tripping over was high at $64.5 \%$ (20/31 cases). Among the traumatic SCI patients with OPLL, the level of OPLL and neurological level of injury matched each other in $92.9 \%$ (39/42 cases).

\section{DISCUSSION}

This study investigated the epidemiologic and demographic characteristics of patients with SCI who were admitted to rehabilitation unit of a university hospital in South Korea. We found a significantly higher proportion of male patients than female patients. Specifically, $76.0 \%$ of the patients were men, with a male-to-female ratio of 3.17:1 (168:53). This result is similar to that of one of the latest Korean epidemiologic study by Shin et al. in

Table 3. Number of cases, mean age and AIS of each non-traumatic etiology

\begin{tabular}{lcccccrr}
\hline $\begin{array}{c}\text { Non-traumatic } \\
\text { etiology }\end{array}$ & $\begin{array}{c}\text { Demyelinating } \\
\text { disease }\end{array}$ & Neoplasm & $\begin{array}{c}\text { Degenerative } \\
\text { disease }\end{array}$ & $\begin{array}{c}\text { Vascular } \\
\text { disease }\end{array}$ & $\begin{array}{c}\text { Infectious } \\
\text { disease }\end{array}$ & Others & Overall \\
\hline Number of cases & $10(16.7)$ & $21(35.0)$ & $5(8.3)$ & $6(10.5)$ & $10(16.2)$ & $8(12.4)$ & $60(100)$ \\
Mean age at injury & $60.0 \pm 9.1$ & $62.3 \pm 18.0$ & $60.8 \pm 9.6$ & $64.0 \pm 20.5$ & $59.1 \pm 16.0$ & $56.6 \pm 13.6$ & $60.7 \pm 15.2$ \\
AIS $^{\text {a) }}$ & & & & & & & \\
A & $0(0)$ & $0(0)$ & $0(0)$ & $1(16.7)$ & $1(10.0)$ & $0(0)$ & $2(3.3)$ \\
B & $0(0)$ & $0(0)$ & $0(0)$ & $0(0)$ & $1(10.0)$ & $0(0)$ & $1(1.7)$ \\
C & $1(10.0)$ & $3(14.3)$ & $0(0)$ & $1(16.7)$ & $1(10.0)$ & $2(25.0)$ & $8(13.3)$ \\
D & $9(90.0)$ & $18(85.7)$ & $5(100.0)$ & $4(66.7)$ & $7(70.0)$ & $6(75.0)$ & $49(81.7)$ \\
\hline
\end{tabular}

Values are presented as mean \pm standard deviation or number $(\%)$.

AIS, American Spinal Injury Association impairment scale.

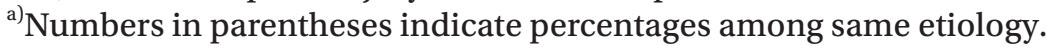

Table 4. Number and prevalence of cases with OPLL among traumatic spinal cord injury patients

\begin{tabular}{lcccccc}
\hline \multicolumn{1}{c}{ Traumatic etiology } & MVC & Fall off & Trip over & Sports injury & Other trauma & Overall \\
\hline Cases with OPLL & $13(22.8)$ & $7(11.7)$ & $20(64.5)$ & $0(0)$ & $2(33.3)$ & $42(26.1)$ \\
Cases without OPLL & $44(77.2)$ & $53(88.3)$ & $11(35.5)$ & $7(100)$ & $4(66.7)$ & $119(73.9)$ \\
\hline
\end{tabular}

Values are presented as number (\%).

MVC, motor vehicle crashes; OPLL, ossification of posterior longitudinal ligament. 
2013, which showed that $74.1 \%$ of patients with all-cause SCI were men, with a male-to-female ratio of 2.86:1 [16]. This sex imbalance was more profound in traumatic SCI patients, with a male-to-female ratio of 4.96:1 (134:27), which is consistent with or more significant than that in previous epidemiologic studies in Korea $[14,16,17]$. This tendency of dominance of male cases in traumatic SCI is also consistent with previous epidemiologic studies in other developed countries [28,31]. Meanwhile, nontraumatic SCI showed smaller difference in the sex ratio at 1.30:1 (34 males, 26 females) in our study, which is closely consistent (1.47:1) with recent study by Shin et al. [16].

With respect to the etiology of traumatic SCI, our study showed that falls, counting low and high falls together, was the single most common cause, accounting for $56.5 \%$ ( $\mathrm{n}=91$ ) of all traumatic causes, followed by MVCs at $35.4 \%$ $(\mathrm{n}=57)$. The dominance of falls as a cause of traumatic SCI in our study is consistent with the trend of recent studies on traumatic SCI epidemiology $[9,28,31,32]$. This trend of changes in etiology is relatively recent finding in Korea. From 1987-1996 to 2004-2008, the proportion of MVC and falls both increased from $57.6 \%, 26.4 \%$ to $60.3 \%, 33.9 \%$, relatively [16]. However, comparing the etiology from 2004 to 2014, the proportion of MVC decreased from $64 \%$ to $45 \%$ and falls increased from $23 \%$ to $43 \%$ [17].

It is also assumed that the older mean age of the patients at the onset of trauma in our study might have contributed to this result. According to the population data from Statistics Korea, the proportion of people older than 60 increased from $14.4 \%$ to $21.6 \%$ between 2008 and 2018 [33] (Fig. 1). Comparing our study results with the previous study of Shin et al. [16], the proportion of people older than 60 among traumatic SCI patients increased

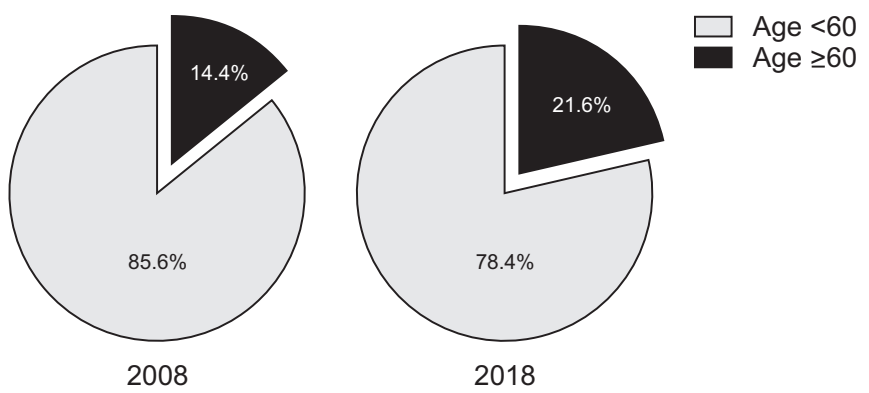

Fig. 1. Changes in proportion of elderly people among Korean population. from $20.0 \%$ to $33.5 \%$, from $2004-2008$ to $2012-2018$. Changes in the mean age at overall SCI and proportion of the patients older than 60 are shown in Fig. 2. Shin et al. [16] reported that falls was the most common cause of injury in people older than 60 years, with falls accounting for $54.2 \%$ of all traumatic causes in this age group. In our study the proportion of falls was highest among all causes of traumatic SCI in the patients aged 60 years or older, accounting for $68.5 \%$. Similar trend is observed in other developed countries. In the United States, falls are the leading cause of SCI among persons aged over 60 years accounting for $55.8 \%$ [12]; in Norway, falls accounted for $65 \%$ of all injuries in persons older than 60 years $[9,31]$. In the United States, the mean age at SCI onset tended to be consistent and then gradually increased. In the 1970s, the mean age was 28.7 years, but it increased to 37.6 years in 2000-2004 and to 43.1 years in 2015-2019 showing increasing ages in all causes of SCI [12]. In Korea, the mean age at SCI onset was 32.3 years in 1985 and increased to 43.6 years in 1999. In our study, the mean age at SCI was 52.8 years, and $39.82 \%$ of the overall SCI patients were aged 60 years or older.

Our study counted low fall and high fall separately to place them into low-energy trauma and high-energy categories. In total, 60 and 31cases of traumatic SCI were attributed to high fall and low fall, respectively. Among the 54 patients aged over 60 years, 14 patients were injured from high fall, accounting for $25.9 \%$ of all traumatic causes in this age group. Twenty-three patients in the same age group were injured by low fall, accounting for $42.6 \%$ of all traumatic causes in this age group. A similar

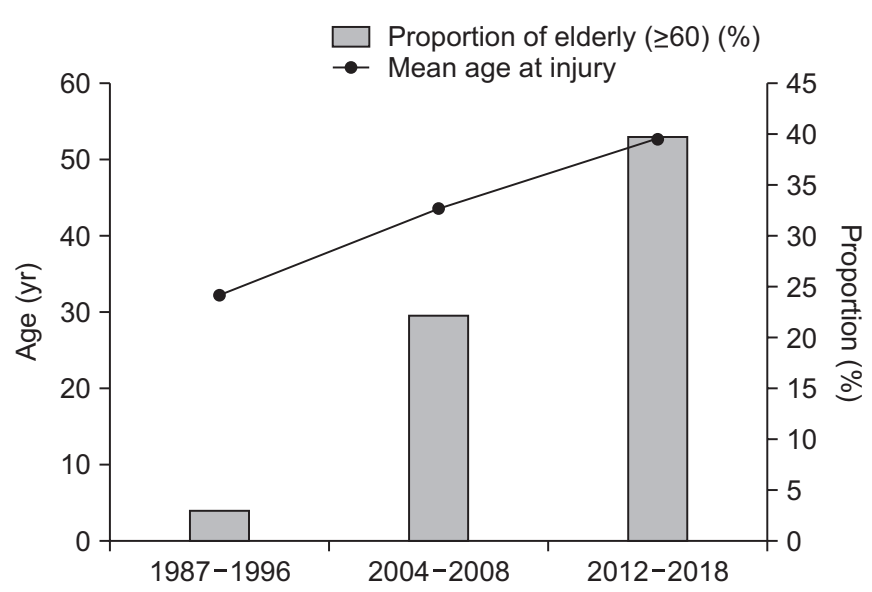

Fig. 2. Changes in proportion of elderly patients and mean age at injury. 
tendency is also found in the United States. Compared with other age groups, the elderly had the highest frequency of low falls on the same level, from the stairs, and slipping and stumbling [32]. The incidence of fall-related traumatic SCIs appeared to be age dependent, particularly for low fall injuries. In traumatic SCIs, the proportion of SCI from falls increased with age; $14.4 \%, 38.7 \%, 55.8 \%$ in $0-45,46-60$, over 61 age groups, respectively [12].

In this study, we investigated the prevalence of OPLL in SCI patients, which is a common comorbidity for Asians. OPLL contributes to the occurrence of low-energy traumatic SCI, particularly, cervical cord injury when low fall accidents happen. Among the 31 patients with traumatic SCI who experienced low fall injuries, 20 (64.5\%) had underlying OPLL. This proportion is much higher than the $0.6 \%-4.6 \%$ prevalence of incidental finding in the normal population in previous national studies $[23,25,34]$. In those studies, OPLL was prevalent in $16.9 \%$ of men aged over 65 years, which is higher than that in younger people, but still far lower than among the patients who experienced low falls in our study. This tendency of higher prevalence of OPLL in older patients supports our findings that show a correlation between higher mean age of traumatic SCI patients and incomplete cervical cord injury caused by low fall event.

Among non-traumatic etiologies, neoplasm was the single most common cause of SCI, accounting for $35.0 \%$, followed by demyelinating disease and infectious disease as the second most common causes ( $16.7 \%$ each). Vascular disease accounted for $10 \%$ and degenerative disease followed at $8.3 \%$. Other causes including herniated ver-

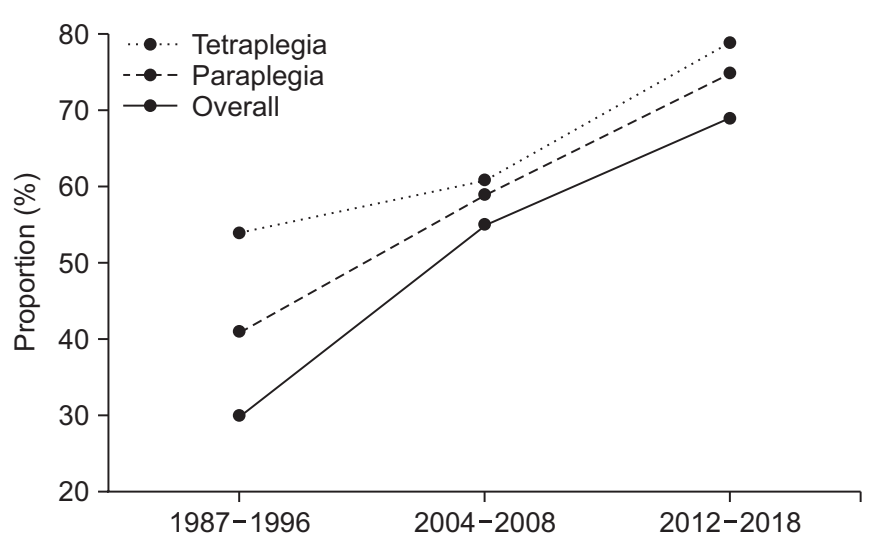

Fig. 3. Changes in proportion of incomplete spinal cord injury. tebral disc, spinal stenosis accounted for $13.3 \%$ of nontraumatic SCI.

With respect to disability types and severity of injury, the epidemiologic study by Shin et al. [16] in 2013 showed incomplete tetraplegia as the most common type, accounting for $36.9 \%$ of all SCI. According to annual reports of NSCISC [12] and as Jain et al. [35] suggest, the proportion of cervical spinal cord injury and incomplete injury has increased gradually in United States. In our study, 127 (54.3\%) patients had tetraplegia, and only 27 (21.3\%) among them presented complete injury. Gradual increase in the proportion of incomplete injury from 1987-1996 to 2012-2018 according to previous study and our study results is shown in Fig. 3 [16]. A notably low proportion of complete injury might be attributed to not only developments in prompt medical and surgical management after SCI, but also the increase in low-energy trauma injuries. In our study, the mean age of patients was higher than that in previous studies, and incomplete tetraplegia was the most common result after low-energy trauma. Among 31 patients who were injured by low fall, 27 (87.1\%) had tetraplegia, and only 4 among them presented complete injury.

There are several limitations in this study. The data source for this study was limited to one university hospital and is not population based. Therefore, our study results might not be generalizable to the overall population of people with SCI in Korea. Also, we could only acquire information from the patients who were admitted or transferred to the rehabilitation medicine department of our hospital. Thus, we could not evaluate SCI patients who died or were discharged before transferring to our department. This might result in underestimation of the fatal SCI or less severe SCI. In addition, we could only check the patients' AIS upon admission or when they were transferred to our department. Therefore, the timing of evaluation of severity and type of SCI varied, and this which could have influenced the severity of injury itself. Lastly, we did not analyse specific types of OPLL in the traumatic SCI patients. It would be meaningful to specify the type of OPLL in correlation with the SCI in further study. Despite these limitations, our study remains valuable because to our best knowledge, this is the latest study that reports the epidemiology and etiology of SCI in Korea.

In conclusion, this study demonstrates the cross-sec- 
tional analysis of the clinicodemographic characteristics of SCI patients in a university hospital in South Korea and showed its similarity with that of other developed, aging countries in Europe and North America. The epidemiology of SCI in Korea might be characterized by high mean age at time of injury and dominance of falls, especially low falls, as a cause of traumatic SCI.

\section{CONFLICT OF INTEREST}

No potential conflict of interest relevant to this article was reported.

\section{AUTHOR CONTRIBUTION}

Conceptualization: Kim HS, Lim KB, Yoo J. Methodology: Kim HS, Kim J, Yoo J. Formal analysis: Kim J, Kang J, Lee H, Lee SW. Project administration: Kim HS, Yoo J. Visualization: Lim KB, Kang J, Lee H. Writing - original draft: Kim HS, Yoo J. Writing - review and editing: Lim KB, Kim J. Approval of final manuscript: all authors.

\section{REFERENCES}

1. DeVivo MJ. Causes and costs of spinal cord injury in the United States. Spinal Cord 1997;35:809-13.

2. Price C, Makintubee S, Herndon W, Istre GR. Epidemiology of traumatic spinal cord injury and acute hospitalization and rehabilitation charges for spinal cord injuries in Oklahoma, 1988-1990. Am J Epidemiol 1994;139:37-47.

3. Sekhon LH, Fehlings MG. Epidemiology, demographics, and pathophysiology of acute spinal cord injury. Spine (Phila Pa 1976) 2001;26(24 Suppl):S2-12.

4. Sohn S, Kim J, Chung CK, Lee NR, Sohn MJ, Kim SH. A nation-wide epidemiological study of newly diagnosed primary spine tumor in the adult Korean population, 2009-2011. J Korean Neurosurg Soc 2017;60:195-204.

5. Pickett GE, Campos-Benitez M, Keller JL, Duggal N. Epidemiology of traumatic spinal cord injury in Canada. Spine (Phila Pa 1976) 2006;31:799-805.

6. Cook DJ, Cusimano MD, Tator CH, Chipman ML. Evaluation of the ThinkFirst Canada, Smart Hockey, brain and spinal cord injury prevention video. Inj Prev 2003;9:361-6.
7. Shults RA, Sleet DA, Elder RW, Ryan GW, Sehgal M. Association between state level drinking and driving countermeasures and self reported alcohol impaired driving. Inj Prev 2002;8:106-10.

8. Wesner ML. An evaluation of Think First Saskatchewan: a head and spinal cord injury prevention program. Can J Public Health 2003;94:115-20.

9. Devivo MJ. Epidemiology of traumatic spinal cord injury: trends and future implications. Spinal Cord 2012;50:365-72.

10. DeVivo MJ, Chen Y. Trends in new injuries, prevalent cases, and aging with spinal cord injury. Arch Phys Med Rehabil 2011;92:332-8.

11. Jackson AB, Dijkers M, Devivo MJ, Poczatek RB. A demographic profile of new traumatic spinal cord injuries: change and stability over 30 years. Arch Phys Med Rehabil 2004;85:1740-8.

12. National Spinal Cord Injury Statistical Center. 2019 annual report - complete public version. Birmingham, AL: National Spinal Cord Injury Statistical Center; 2019.

13. Ning GZ, Wu Q, Li YL, Feng SQ. Epidemiology of traumatic spinal cord injury in Asia: a systematic review. J Spinal Cord Med 2012;35:229-39.

14. Han ZA, Lee BS, Kim W, Lee SJ, Im HJ, Kim C, et al. People with spinal cord injury in Korea. Am J Phys Med Rehabil 2017;96(2 Suppl 1):S83-5.

15. Park CI, Shin JC, Kim SW, Jang SH, Chung WT, Kim HJ. Epidemiologic study of spinal cord injury. J Korean Acad Rehabil Med 1999;23:267-75.

16. Shin JC, Kim DH, Yu SJ, Yang HE, Yoon SY. Epidemiologic change of patients with spinal cord injury. Ann Rehabil Med 2013;37:50-6.

17. National Rehabilitation Center. National Rehabilitation Center SCI Database. Seoul, Korea: National Rehabilitation Center; 2014.

18. Ackery A, Tator C, Krassioukov A. A global perspective on spinal cord injury epidemiology. J Neurotrauma 2004;21:1355-70.

19. Lee BB, Cripps RA, Fitzharris M, Wing PC. The global map for traumatic spinal cord injury epidemiology: update 2011, global incidence rate. Spinal Cord 2014;52:110-6.

20. Eurostat. Population structure and ageing 2008-2018. Luxembourg, Luxembourg: Eurostat; 2018.

21. Statistics Korea. 2018 senior statistics. Daejeon, Korea; 
Statistics Korea; 2018.

22. He W, Goodkind D, Kowal P. An aging world 2015. Washington, DC: US Census Bureau; 2016.

23. Sohn S, Chung CK, Yun TJ, Sohn CH. Epidemiological survey of ossification of the posterior longitudinal ligament in an adult Korean population: threedimensional computed tomographic observation of 3,240 cases. Calcif Tissue Int 2014;94:613-20.

24. Inamasu J, Guiot BH, Sachs DC. Ossification of the posterior longitudinal ligament: an update on its biology, epidemiology, and natural history. Neurosurgery 2006;58:1027-39.

25. Jin BH, Kim YS. Ossification of spinal ligaments. J Korean Neurosurg Soc 1991;20:875-84.

26. Fujimori T, Le H, Hu SS, Chin C, Pekmezci M, Schairer $\mathrm{W}$, et al. Ossification of the posterior longitudinal ligament of the cervical spine in 3161 patients: a CTbased study. Spine (Phila Pa 1976) 2015;40:E394-403.

27. Saetia K, Cho D, Lee S, Kim DH, Kim SD. Ossification of the posterior longitudinal ligament: a review. Neurosurg Focus 2011;30:E1.

28. Chamberlain JD, Deriaz O, Hund-Georgiadis M, Meier S, Scheel-Sailer A, Schubert M, et al. Epidemiology and contemporary risk profile of traumatic spinal cord injury in Switzerland. Inj Epidemiol 2015;2:28.

29. DeVivo MJ, Biering-Sorensen F, New P, Chen Y; Inter- national Spinal Cord Injury Data Set. Standardization of data analysis and reporting of results from the International Spinal Cord Injury Core Data Set. Spinal Cord 2011;49:596-9.

30. Knutsdottir S, Thorisdottir H, Sigvaldason K, Jonsson $\mathrm{H}$ Jr, Bjornsson A, Ingvarsson P. Epidemiology of traumatic spinal cord injuries in Iceland from 1975 to 2009. Spinal Cord 2012;50:123-6.

31. Halvorsen A, Pettersen AL, Nilsen SM, Halle KK, Schaanning EE, Rekand T. Epidemiology of traumatic spinal cord injury in Norway in 2012-2016: a registrybased cross-sectional study. Spinal Cord 2019;57:3318.

32. Chen Y, Tang Y, Allen V, DeVivo MJ. Fall-induced spinal cord injury: external causes and implications for prevention. J Spinal Cord Med 2016;39:24-31.

33. Ministry of the Interior and Safety. Statistics of residence registration population 2008-2018. Sejong, Korea: Ministry of the Interior and Safety; 2019.

34. Kim TJ, Bae KW, Uhm WS, Kim TH, Joo KB, Jun JB. Prevalence of ossification of the posterior longitudinal ligament of the cervical spine. Joint Bone Spine 2008;75:471-4.

35. Jain NB, Ayers GD, Peterson EN, Harris MB, Morse L, O'Connor KC, et al. Traumatic spinal cord injury in the United States, 1993-2012. JAMA 2015;313:2236-43. 